УДК 378

$10.17213 / 2075-2067-2020-5-33-41$

\title{
АКАДЕМИЧЕСКОЕ ЛИДЕРСТВО: ДВИЖЕНИЕ К ТРАНСПРОФЕССИОНАЛЬНОЙ ИДЕНТИЧНОСТИ В РЕГИОНАЛЬНОМ ПРОСТРАНСТВЕ ВЫСШЕГО ОБРАЗОВАНИЯ ${ }^{1}$
}

(C) 2020 г. К. В. Воденко, А. К. Дегтярев, Н. С. Иваненко

\section{Южсно-Российский государственный политехнический университет (НПИ) имени М. И. Платова, г. Новочеркасск, Россия}

Цель исследования. В данной статье актуализируется сложная проблема влияния академического лидерства на развитие транспрофессиональной идентичности, изменяющей облик современного инженера.

Методология исследования. Реализуя заявленную изель исследования, авторский коллектив опирается на сочиоресурсный подход с включением процедур институционализма и функииональности.

Результаты исследования. В результате обосновываются выводы об академическом лидерстве как исходном условии развития транспрофессиональной идентичности. Отмечается, что академическое лидерство как совокупность возможностей и условий для профессиональной подготовки влияет на транспрофессиональную идентичность, во-первых, субстанционально как сохранение академизма в рамках инновационной активности и, во-вторых, функиионально в контексте закрепления транспрофессиональной идентичности как критерия принятия новых форм академического лидерства.

Перспективы использования результатов исследования. Результаты исследования могут использоваться для дальнейших исследований академического лидерства в социально-гуманитарном дискурсе, а также для развития системы образования как на федеральном, так и региональном уровнях.

Ключевые слова: академическое лидерство; транспрофессиональная идентичность; дигитализация; региональное пространство; высшее образование; будущий инженер.

ACADEMIC LEADERSHIP:

\section{MOVEMENT TOWARDS TRANSPROFESSIONAL IDENTITY} IN THE REGIONAL HIGHER EDUCATION SPACE

\section{(C) $2020 \quad$ K. V. Vodenko, A. K. Degtyarev, N. S. Ivanenko}

\section{Platov South Russian State Polytechnic University (NPI), Novocherkassk, Russia}

Purpose of research. This article focuses on the complex problem of the influence of academic leadership on the development of a transprofessional identity that changes the face of a modern engineer.

1 Статья выполнена в рамках реализации гранта Президента Российской Федерации для государственной поддержки ведущих научных школ Российской Федерации (НШ-2582.2020.6) на тему «Государственная политика в сфере высшего образования и развитие инновационного потенциала молодежи: экономические и неэкономические детерминанты и механизмы в условиях регионализации социального пространства и становления Индустрии 4.0». 
Research methodology. Implementing the stated goal of the research, the authors'team relies on a socio-resource approach with the inclusion of institutionalism and functionality procedures.

Research result. As a result, the conclusions about academic leadership as the initial condition for the development of transprofessional identity are substantiated. It is noted that academic leadership as a set of opportunities and conditions for professional training affects transprofessional identity, firstly, substantively as the preservation of academism in the framework of innovation activity and, secondly, functionally in the context of consolidating transprofessional identity as a criterion for accepting new forms of academic leadership.

Prospects for using the research results. The results of the research can be used for further research of academic leadership in social and humanitarian discourse, as well as for the development of the education system both at the Federal and regional levels.

Key words: academic leadership; transprofessional identity; digitalization; regional space; higher education; future engineer.

Введение. Академическое лидерство введено в научно-исследовательский оборот российской гуманитарной мысли в рамках происходящих перемен в сфере регионального высшего образования. Акцент смещается от приоритета качества и доступности высшего образования к вопросу о развитии транснациональной идентичности. Дело в том, что когда мы признаем значимость качества и доступности высшего образования, значимым становится интерпретация качества в контексте повышения мобильности высшего образования, доступности - возможности через мобильность осваивать новые профессиональные навыки и выходить в новые профессиональные ниши [1].

Не секрет, что высшее образование в российском региональном пространстве характеризуется показателями иммобильности, сокращением научно-исследовательских контактов и проектов, ростом территориальных барьеров на пути перемещения студентов и особенно угасанием роли межрегионального сотрудничества в развитии высшего образования. По сравнению с предшествующим периодом конца 90-х - начала 2000-х годов не только сошли на «нет» формы межрегионального экономического сотрудничества, но и в рамках стандартизации регионального пространства высшее образование в регионе было включено в централизованную схему управления, в которой низок уровень заинтересованности в приобретении образовательных активов через новые образовательные практики из других российских регионов.
В большой степени приоритетом обладает политика «исправления ошибок прошлого», создание механизмов контроля и регулирования для внедрения официально утвержденных профессионально-образовательных стандартов, что имеет последствием и ослабление регионального компонента высшего образования, и прекращение активного инвестирования со стороны государства, которое, исходя из фискальных и политических соображений, нацелено на оптимизацию высшего образования. Логика таких действий объясняется тем, что в условиях унификации достижение равенства через несамостоятельность и зависимость от регулирующих структур для региональной образовательной системы реальной становится стратегия адаптации к нивелирующим условиям, а регионализация является избыточной и рискогенной.

Избыточной — в смысле напряженности с финансированием региональных образовательных проектов, рискогенной - в том, что могут возникнуть источники напряженности по поводу сомнительных инноваций и критической оценки со стороны регулирующих органов. Здесь важно подчеркнуть, что в России не действует европейский опыт софинансирования региональных и межрегиональных проектов, и кроме того, стратегия развития высшего образования в региональном пространстве подразумевает определение факторов перемен через государственный и технологический аспекты развития. Они связаны тем, что нынешняя волна интереса к дигитализации высшего образования основывается 
на государственной программе цифровизации всех сфер общественной жизни (экономики, социальной жизни, образования), где есть противоречия с регионализацией, с тем, что трактуется как влияние социокультурной специфики региона.

Необходимая дискуссия о путях развития высшего образования в региональном пространстве замещается воспроизводством свойственных для XX века споров о влиянии технократизма на образование или рисках образовательного сепаратизма. Реально не определяются схемы взаимодействия дигитализации и регионализации, которые имеют общий контур действий в понимании дигитализации как способа регионализации высшего образования в современных условиях.

Речь идет о том, что регионализация высшего образования осмысленна и имеет общественную полезность, если направлена на рост социальной и экономической конкурентности региона, повышение качества человеческого капитала, привлечение инвестиций на развитие региона. Не менее важный фактор состоит в том, что в контексте регионализации есть возможности для принятия позиции ускорения социального развития региона, запуска проектов долгосрочного обслуживания и обеспечения сферы высшего образования. Другими словами, регионализация как процесс ставит дигитализацию в рамки концентрации образования на передовых инновационных отраслях (телекоммуникации, биотехнологии, формацевтика, агроиндустрия). Таким образом, идея реиндустриализации региона как возрождение традиционных базисных сфер (к примеру, металлургии или машиностроения) перестает быть идеологией для высшего образования в целях расширения подготовки инженеров-специалистов, которые могут испытывать влияние изменений на рынке труда и необходимости новых путей профессиональной мобильности.

Методология исследования. Исходя из вышесказанного, следует отметить, что определенная неясность как следствие «кроссинга» анализируемых понятий приводит к двум выводам. Во-первых, в рамках реализуемого исследования целью является анализ транспрофессиональной мобильной идентичности академического лидерства как индикатора профессиональной идентичности в контексте дигитализации и регионализации высшего образования. Мы неслучайно не останавливались на понятии академического лидерства не только вследствие неукоренённости в исследовательском дискурсе, но и по причине полисемантичности, то есть «эпистемологической пустоты». Академическое лидерство интерпретируется в рамках резистентности переменам в системе высшего образования последствием дигитализации, которая смещает показатели лидерства с парадигмальных достижений от авторитета в научной среде к индикаторам информатизации (цифровизации), внедрения новейших методов обучения и подготовки к росту роли виртуализации.

К тому же академическое лидерство испытывает влияние ограничивающих факторов, связанных с размытием вертикальных внутринаучных связей, с тем, что наблюдается исчезновение традиционных школ и направленияй в условиях роста междисциплинарных исследований. Сложившийся фон если и вызывает неприятие академического лидерства, то возникает парадокс деакадемитизации, связанный с тем, что из лидерства исчезает понятие «академический», которое ассоциируется с фундаментальностью, классицизмом высшего образования, которое исторически сложилось в немецком варианте инженерно-технического образования. Однако в современных условиях, когда инженерная профессия испытывает вызовы дигитализации рынка, создающие эффект устарелости познания, есть необходимость определить методологические основания анализа академического лидерства в рамках альтернативы традиционной инженерной профессиональной мобильности.

На первый взгляд, работает функциональная схема, по которой «выходом» академического лидерства является выпуск востребованных и конкурентноспособных инженеров. Актуализирована и другая методологическая схема, в которой академическое лидерство измеряется по диспозиционному критерию в установках на академическое лидерство как приоритетность в подготовке инженеров нового типа, способных реализовать стратегию образования на всю жизнь и действовать по схеме готовности к перемене профессии.

Рассматриваемые подходы имеют обоснование в сложившейся ситуации в высшем 
образовании в региональном пространстве, т.к. траектории его развития привязывают к инновационным изменениям и при этом характеризуют профессиональную мобильность в качестве ориентира академического лидерства. Но исследователь обязан учитывать сложности, связанные с тем, что академическое лидерство является трактуемым по «традиции», и с тем, что академичность требует создания институциональной среды, обеспечивающей стратегическое функционирование механизмов координации и саморегуляции в сфере высшего образования. В рамках институционального подхода академическое лидерство обеспечивается адаптацией образовательных центров к требованиям согласования интересов образования и реальных секторов социально-экономической жизни. Важным становится организационный показатель академического лидерства, который включает приоритет поиска способов адаптации к переменам в региональном образовательном пространстве, расширения лидерства на основе критериев коммуникативности и деловитости, а также новых институционных практик, направленных на рост транспрофессональной мобильности.

Такая постановка проблемы влечет необходимость изучения готовности институтов профессионального образования к формированию у будущих специалистов способности перемены профессии, акцента на профессионализм как умения в изменившихся обстоятельствах нацеливаться на запрос регионального социума в специалистах нового типа.

Таким образом, методологически академическое лидерство может анализироваться на базе монокритериальности, но, скорее, успешным является принцип методологической дуальности, сочетающий показатели функциональности и институционализацию академического лидерства. Интересно, что в данном контексте образцовой является германская модель дуального образования, то есть в имеющейся ситуации германское образование становится «академическим». Если говорить о методологическом инструментарии, очевидно, что академическое лидерство в российском региональном пространстве может включать при расшифровке обоснованных выше критериев значимость их влияния на транспрофессиональную подготовку [2].
В этом контексте критерий функциональности является объективным, т.к. характеризует количественный состав транспрофессональной идентичности, плотность в различных сфеpax социально-экономической деятельности. Субъектным критерием выступает ресурсность акторов регионального образовательного пространства по отношению к подготовке и реализации стратегии академического лидерства. Таким образом, подытоживая выше сказанное, мы придерживаемся схемы социоресурсного подхода, включающего функциональные институциональные процедуры.

\section{Результаты и выводы исследования.} На стадии продвижения и распространения академического лидерства в образовательной среде выявляется степень востребованности непосредственных и опосредованных результатов воздействия академического лидерства на транспрофессиональной идентичности. В рамках реализации целей исследования важным становится использование статистики относительно актуализации программ академического лидерства в конкретных образовательных структурах. Важным также является показатель соотнесения академического лидерства с научно-инновационными проектами. Это проблемный момент исследования, т.к. академическое лидерство, повторимся еще раз, ассоциируется и воспринимается в рамках парадигмы классического образования, в то время как инновационность определяется как показатель современного неклассического образования.

Между тем степень реализации научноинновационных проектов не может интерпретироваться вне связи с академическим лидерством: акцент на подготовку специалистов по инновационному критерию предполагает профессиональную компетентность на уровне знания базовых принципов академического лидерства. Если понимать академическое лидерство в аналитическом смысле, то следует дефинировать это понятие как совокупность качеств, свойств и параметров, определяющих состояние образовательной среды регионального пространства как вектор развития профессиональных исследовательских проективных ресурсов акторов образования [3].

По нашему мнению, подобная квалификация лидерства слабо внедрена в образова- 
тельную среду и не актуализируется в сравнительном анализе эффективности региональных образовательных систем. Следствием данного упущения является искажаемость результатов относительно выпуска инженеров-специалистов, шансов трудоустройства, возможности перемены профессии. Часто акцент общественного внимания, а иногда и социологической экспертизы смещается на анализ показателей выпуска вне выявления готовности к принятию транспрофессиональной идентичности. Полагается, что акторы образования в региональном пространстве активны по логике профильности, в то время как перемена профессии воспринимается в качестве вынужденной адаптации к условиям недостаточной востребованности и низкой престижности и доходности.

Включение академического лидерства как механизма транспрофессиональной идентичности означает, что в нынешних условиях транспрофессиональная идентичность является параметром осознания акторами высшего образования принадлежности к инженерному слою как имеющему открытые границы идентификационного выбора. Профессионализм в этом значении является маркером мобилизационных качеств актора. Если же проанализировать влияние академического лидерства, то позитивные результаты закрепления транспрофессиональной идентичности выражаются в академизме акторов образования как обладающих профессиональными и культурными горизонтами для перехода в иную профессиональную нишу.

В традиционном варианте транспрофессиональная идентичность может определяться как свойство компенсации неудач в достижении профессионализма, и таким образом, транспрофессиональность может интерпретироваться как «недопрофессионализм». Для нас актуальна оценка эффективности и результативности академического лидерства в рамках его реализации на этапах становления, распространения и достижения зрелого состояния. Это замечание существенно, так как практически в региональной образовательной среде академическое лидерство находится в проективном состоянии, а навязывание схемы академического лидерства как признака элитного образования резко снижает заинтересованность региональных вузов, не входя- щих в разряд элитных, к поиску адекватных форм академического лидерства [4].

Следует подчеркнуть, что само понятие академического лидерства, так же как установка акторов образования на его принятие в качестве основы для транспрофессиональной идентичности, может становиться доминирующим в идентификационном выборе будущих инженеров. Совершенствование профессиональной подготовки будущих инженеров, таким образом, предполагает внесение изменений в профессиональный кодекс инженеров, формирование того, что инженерная профессия обладает плавающей идентичностью и что данный фактор становится конституциирующим и стимулирующим транспрофессиональной идентичности. Как показывает европейский опыт (Финляндия), лидирующие позиции в современных технологиях связаны с продуманной государственной инновационной политикой, но вероятно, позитивную роль сыграл тот факт, что в Финляндии традиционный академизм не определял траекторию развития образования и выражался на уровне заимствования образцов немецкой классической школы.

Образовательная система Финляндии после обретении независимости в 1918 г. работала в режиме использования модели «прикладного образования», было сознание того, что копирование классического академизма создает ситуацию запаздывания и практически сужает границы инноваций, которые необязательно должны быть «освещены» авторитетом академизма.

Во Франции, по сравнению с Финляндией, очевиден академический «рецидивизм», где постоянно производится спор между классическим образованием (Эколь де Франс) и новыми университетами (Нантер). Данный спор излишне затянулся и, хотя несколько потерял «классовую» окраску, является фактором, снижающим интерес к принятию академического лидерства в новом прочтении, связанным с корреспондированием между новыми технологиями и установкой акторов образования на транспрофессиональную идентичность.

Хотя Франция обладает хорошим научным потенциалом и занимает ведущее место во внедрении инноваций, следует говорить о том, что границы транспрофессиональной 
идентичности во французском варианте не являются широкими. В основном французские инженеры - профессионалы своего дела, занятые в масштабных инновационных проектах (энергетика, аэрокосмическая отрасль, телекоммуникации), где важным является обретение новых профессиональных качеств при сохранении инженерной профильности.

Финский опыт отсечен тем, что транспрофессиональная идентичность актуализируется в контексте новых технологий, работающих в сфере среднего и малого бизнеса. Можно сделать вывод о том, что в сравнении Франции и Финляндии как имеющих различные модели академического лидерства (субстанциональная и функциональная) финская предполагает принятие транспрофессиональной идентичности как перспективной для развития экономики, в то время как французская содержит признание академического лидерства в опосредованной связи с транспрофессиональной идентичностью.

При этом первостепенное значение уделяется возможностям снизить влияние транспрофессиональности, направленное на перемену профессии, и ее интерпретации как способа профессиональной переподготовки инженера. Это подтверждается тем, что новые технологии по французской модели производятся в исследовательских центрах по критерию узкого профессионализма. В Финляндии речь идет о том, что новые технологии формируются в практическом секторе и не обращены к запросу на радикальные изменения в образовательной системе [5].

Механизмы обновления в сфере академического лидерства содержат возможность изменений в активности акторов образования как следствие их участия в практических проектах. Таким образом, не претендуя на восхваление или на критику анализируемых моделей, следует учитывать, что в России ни одна из этих моделей не может быть принята в чистом виде, что в региональном образовательном пространстве есть инновационный сдвиг (Иннополис в Татарстане) и классический (Самара в России). Это является констатацией неоднородности академического лидерства, если использовать ресурсный критерий.

В поиске компромиссного варианта, актуального для реализации заявленной цели исследования, необходимо рассматривать академическое лидерство в двух аспектах: как способ сохранения преемственности образования в региональном пространстве, консолидированности позиции оценок по поводу того, каков научно-исследовательский потенциал образования в региональном пространстве и в той же степени значим, каков вектор развития будущих инженеров, динамика их идентификационных стратегий.

В этом случае транспрофессиональная идентичность не может рассматриваться в качестве нормативной, иметь функциональную основу: там, где региональное образование отражает запрос на развитие масштабных инновационных проектов, очевидно, что транспрофессиональная идентичность может использоваться как альтернатива традиционному профессионализму в качестве решения проблемы переизбытка инженеров.

Если образовательная система в регионе движется по траектории множественности инновационных проектов и работает в режиме «сборки», очевидно, что академическое лидерство является условием ограничения экспансии транспрофессиональной идентичности как способной привести к «амнезии» академической традиции.

Очевидно, что исследование роли академического лидерства в формировании транспрофессиональной идентичности требует принятия процедур, обязывающих рассматривать системно и позиции акторов образования по поводу транспрофесиональной идентичности и влияния технологических, организационных, поведенческих изменений. Следует сделать вывод, что необходимо отказаться от технологического детерминизма и видеть влияние инноваций через позиции акторов регионального образования относительно того, что для них определяет смысл академического лидерства.

В анализируемом аспекте академического лидерства, принимающем в нашем исследовании статус исходной предпосылки транспрофессиональной идентичности, важно определить то, каким образом будет обеспечена возможность создания малых и средних инновационных предприятий на основе вуза, расширение полномочий руководителя и придание транспрофессиональной идентичности параметров компетентности. Зада- 
чи, которые стоят в этом смысле, специфичны, поскольку приходится двигаться в условиях неопределенности рамочных правил и образцов внедрения и актуализации новых форм академического лидерства.

Исходя из этого, можно определить комплекс внутренних и внешних стимулов и барьеров для роста транспрофессиональной идентичности в контексте академического лидерства. Основываясь на том, что нельзя оценивать транспрофессиональную идентичность вне изменений концепций академического лидерства и в то же время допускать, что установка на транспрофессиональную идентичность акторов образования создает условия для завершения цикла перемен, в понимании академического лидерства есть возможность сделать вывод, что академическое лидерство становится одновременно проблемным и перспективным.

Оно проблемно в том, что фиксирует узлы противоречий развития региональной системы образования в отношении акторов образования ориентироваться на возможности транспрофессиональной идентичности, учебно-подготовительных программ, возможности реализации инновационных проектов. Перспективно в том, что стимулирует поиск новых форм профессиональной подготовки инженеров, исходя из востребованности в будущем, от чего зависит социально-экономическое развитие региона. Академическое лидерство таким образом перестает быть внутренней характеристикой образовательного пространства и вызывает системообразующий эффект и в образовании, и в жизни региона в целом.

Резюме. Реализуя целью исследование академического лидерства в неожиданном для социологического сообщества ракурсе транспрофессионльной идентичности, мы считаем, что полезность произведенного анализа состоит в следующем.

Во-первых, обозначены рамки концептуализации академического лидерства для сложившейся системы регионального образования, что выражается в объективных и субъектных параметрах.

Во-вторых, выбрав в качестве основы исследования социоресурсный подход, мы смогли сформулировать критерии функциональности и ресурсности, анализируя пози- ции акторов региональной системы образования, определить возможные варианты развития транспрофессиональной идентичности при актуализации модели академического лидерства, которую можно квалифицировать как транзитивную, отражающую переход регионального образования в работе на перспективу развития региона.

В-третьих, отмечая сложность анализа соотношения академического лидерства и транспрофесиональной идентичности, мы считаем, что возникает возможность путем нахождения медиаторного показателя как инновационного проектирования сформулировать фиксированные показатели влияния академического лидерства на динамику транспрофессиональной идентичности.

\section{Литература}

1. Проект Постановления Правительства РФ «О мерах государственной поддержки российских образовательных организаций высшего образования в целях научного, технологического и кадрового обеспечения экономики и социальной сферы, повышения глобальной конкурентоспособности системы высшего образования и регионального развития».

2. Волков Ю. Г. Институт лидерства в региональном пространстве. - Ростов-на-Дону; Таганрог: ЮФУ, 2020. - 126 с.

3. Государственное управление научноинновационным развитием: новое в мировой практике: монография / отв. ред. В.И. Кушлин. - М.: Проспект, 2018. - 272 с.

4. Другова E.A. Ключевые характеристики программ преподавательского совершенства для академических лидеров. Обзор опыта высокорейтинговых университетов на материале зарубежных публикаций // Вопросы образования. - 2019. - №4. - С. 8-29.

5. Ахмадулина T. B., Распоров В. М., Pacnoров В. В. Европейский опыт государственного регулирования инновационной деятельности: учеб. пособие / под ред. В.М. Распопова. М.: Магистр: ИНФРА-М, 2019. - 264 с.

\section{References}

1. Proekt Postanovlenija Pravitel'stva RF «O merah gosudarstvennoj podderzhki rossijskih obrazovatel'nyh organizacij vysshe- 
go obrazovanija $\mathrm{v}$ celjah nauchnogo, tehnologicheskogo i kadrovogo obespechenija jekonomiki i social'noj sfery, povyshenija global'noj konkurentosposobnosti sistemy vysshego obrazo-vanija i regional'nogo razvitija» [Draft Decree of the Government of the Russian Federation «On measures of state support of Russian higher education institutions for the purpose of scientific, technological and personnel support of the economy and social sphere, improving the global competitiveness of the higher education system and regional development»].

2. Volkov Ju. G. Institut liderstva $\mathrm{v}$ regional'nom prostranstve [Institute of leadership in the regional space]. - Rostov-on-Don; Taganrog: JuFU, 2020. - 126 p.

3. Gosudarstvennoe upravlenie nauchnoinnovacionnym razvitiem: novoe $\mathrm{v}$ mirovoj praktike: monografija [State management of scientific and innovative development: new in world practice: monograph] / In V.I. Kushlin (eds.). - Moscow: Prospekt, 2018. - 272 p.

4. Drugova E.A. Kljuchevye harakteristiki programm prepodavatel'skogo sovershenstva dlja akademicheskih liderov. Obzor opyta vysokorejtingovyh universitetov na materiale zarubezhnyh publikacij [Key characteristics of teaching excellence programs for academic leaders. Review of the experience of highly ranked universities based on foreign publications] // Voprosy obrazovanija [The issue of education]. - 2019. - №4. - Pp. 8-29.

5. Ahmadulina T.V., Rasporov V.M., Rasporov V.V. Evropejskij opyt gosudarstvennogo regulirovanija innovacionnoj dejatel'nosti: ucheb. posobie [European experience of state regulation of innovative activity] / In V.M. Raspopov (eds.). Moscow: Magistr: INFRA-M, 2019. - 264 p.

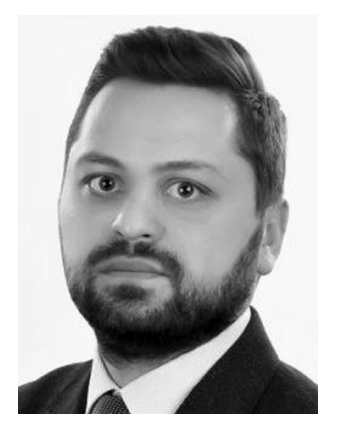

Воденко Константин Викторович - доктор философских наук, профессор, советник при ректорате Южно-Российского государственного политехнического университета (НПИ) имени М.И. Платова. Руководитель научно-образовательной школы «Управление социальными процессами в поликультурном регионе». Сфера научных интересов - социально-культурные и социально-экономические институты и процессы в условиях формирования инновационной модели общественного развития. Руководитель многочисленных прикладных социологических исследований.

Vodenko Konstantin Victorovich - Doctor of Philosophical Sciences, Professor, Adviser to the rector's office, Platov South Russian State Polytechnic University (NPI). Head of the scientific and educational school "Management of social processes in a multicultural region». Research interests - socio-cultural and socio-economic institutions and processes in the formation of an innovative model of social development. Head of numerous applied sociological studies.

346428 , г. Новочеркасск, ул. Просвещения, 132

132 Prosveshcheniya st., 346528, Novocherkassk, Russia

E-mail: vodenkok@mail.ru 


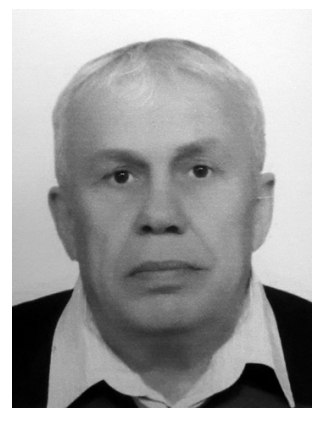

Дегтярев Александр Константинович - доктор философских наук, профессор Южно-Российского государственного политехнического университета (НПИ) имени М. И. Платова.

Degtyarev Alexander Konstantinovich - Doctor of Philosophical Sciences, Professor, Platov South Russian State Polytechnic University (NPI).

346428 , г. Новочеркасск, ул. Просвещения, 132

132 Prosveshcheniya st., 346428, Novocherkassk, Russia

E-mail:rse1985@mail.ru

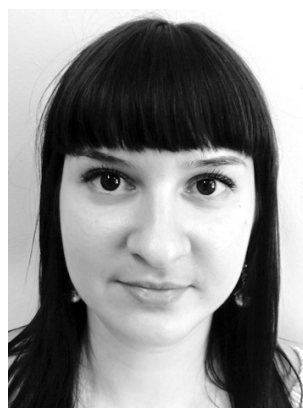

Иваненко Наталья Сергеевна - кандидат социологических наук, доцент кафедры «Социальные и гуманитарные науки» Южно-Российского государственного политехнического университета (НПИ) имени М.И. Платова.

Ivanenko Natalia Sergeevna - Candidate of Sociological Sciences, Associate Professor, Department of Social Sciences and $\mathrm{Hu}-$ manities, Platov South Russian State Polytechnic University (NPI).

346428 , г. Новочеркасск, ул. Просвещения, 132

132 Prosveshcheniya st., 346428, Novocherkassk, Russia

E-mail:79043483051@yandex.ru 